\title{
Vichy y Madrid. Las relaciones hispano-francesas de junio de 1940 a noviembre de 1942
}

\author{
JUAN AVILÉs Farré
}

El régimen que se estableció en Francia tras la derrota de junio de 1940, encabezado por un dictador militar, autoritario y conservador, presentaba evidentes analogías con el que se había impuesto en España en la guerra civil. Ambos eran fascistizantes más que fascistas y eran vistos con cierto desprecio por Hitler, quien en cierta ocasión comentó a Mussolini que la clique formada por "Action Française", los reaccionarios y el clero que dominaba en Vichy, era equivalente a la que rodeaba a Franco ${ }^{1}$. A pesar de ello el régimen de Madrid no mostró cordialidad alguna hacia el de Vichy, en parte por las aspiraciones territoriales españolas hacia el Marruecos francés, en parte por la tradicional reticencia hacia Francia de la derecha nacionalista española y en definitiva porque los franquistas se sentian más identificados con la vencedora Alemania que con la nación vencida que Pétain trataba de encaminar por la nueva senda del autoritarismo. Este artículo tratará de demostrarlo, a partir de la valiosa fuente que constituyen los informes del embajador José Félix de Lequerica. El período cronológico al que se ciñe concluye con el desembarco aliado, en el África del norte en noviembre de 1942, tras el cual el régimen de Pétain perdió las bazas que hasta entonces le habían dado un asomo de autonomía frente a Alemania: la zona libre metropolitana, la flota y las colonias ${ }^{2}$.

1 Lottman, Pétain, París 1984, pág. 367.

${ }^{2}$ Sobre la primera etapa de la gestión de Lequerica en Francia véase mi artículo «Lequerica, embajador franquista en París», en Historia 16, n. 160 (1989), págs. 12-20. 
La formación del Gobierno Pétain, integrado por gentes con las que había tenido estrecho contacto, fue recibida con simpatía por el embajador español. Lequerica opinaba que el nuevo régimen de una orientación similar a los de los vencedores, que Pétain se proponía establecer, representaría un poder libre y auténtico con el que hacer la paz sería mucho más beneficioso para Alemania e Italia que con un gobierno de quintacolumnistas. Preveía sin embargo la dificultad que supondría conciliar la benevolencia de los vencedores necesaria para que se consolidara esa orientación francesa, que era la conveniente para Europa, con la revisión territorial que habría de poner fin a la injusta distribución del mundo que Francia e Inglaterra habian impuesto, revisión de la cual el Gobierno español esperaba beneficiarse. Por parte francesa esto último no se apreció inicialmente. Por el contrario, el ministro de Asuntos exteriores Baudouin contaba con las simpatías españolas hacia su Gobierno, e incluso con una "solidaridad latina y cristiana" que habría de revivir entre "las tres grandes naciones mediterráneas", para que el Gobierno de Madrid usara su influencia a fin de moderar las exigencias de Berlín y Roma hacia Francia. Estas esperanzas se mostraron vanas. A mediados de julio el embajador francés en Madrid, Georges Renom de la Baume, destacaba el tono germanófilo y los ataques a Francia de la prensa española y desaconsejaba toda manifestación exterior de una presunta solidaridad entre ambos países que pudiera ocasionar reacciones desfavorables ${ }^{3}$.

En realidad, tras la derrota de Francia, Franco se planteó la posibilidad de entrar en guerra al lado de Alemania, con la esperanza de participar en los despojos del imperio colonial francés. El 14 de junio se produjo la ocupación de Tánger y el día 16 un enviado del Caudillo, el general Vigón, se entrevistó con Hitler, quien se mostró reticente ante las reivindicaciones territoriales que acompañaban a la oferta de beligerancia española, entre las que se incluían el protectorado de todo Marruecos y otras rectificaciones en África a expensas de Francia. Las aspiraciones españolas fueron también expuestas, en versión muy suavizada, a los propios franceses. El ministro de Asuntos Exteriores Beigbeder manifestó al embajador la Baume que España no arrebataría nada por la fuerza a Francia, pero que ésta debía plantearse la conveniencia de realizar de antemano ciertas concesiones territoriales, a las que quizá se vería obligada en el momento de firmarse la paz. Las posesiones africanas, no

${ }^{3}$ Ministerio de Asuntos Exteriores, Madrid (MAEM), R 2295/4, Lequerica a Beigbeder, París 24/6/40. Ministère des Affaires Extérieures, Paris (MAEP), 247, Baudouin a La Baume, Vichy 3/7/40; La Baume a Baudouin, Madrid 14/7/40. 
ocupadas por Alemania, constituían sin embargo una baza demasiado importante para el régimen de Pétain, como para que éste fuera a ceder fácilmente ${ }^{4}$.

El camino español hacia Marruecos no pasaba en realidad por Vichy, sino por Berlín, a donde a mediados de septiembre viajó Serrano Súñer, partidario de la inmediata entrada en guerra. Hitler sin embargo no deseaba que ésta se produjera al precio de una amputación de las posesiones francesas en África, no ocupadas por Alemania en virtud del armisticio y en la que se mantenían fuerzas armadas importantes, cuya decantación hacia de Gaulle provocaria un problema grave. Según Lequerica el viaje de Serrano fue bien recibido en Vichy, donde se veía con satisfacción el acercamiento de España al Eje, pues se mantenía la esperanza de poder utilizar la amistad española como baza frente Alemania. El principal obstáculo a dicha amistad eran las reivindicaciones marroquies de España, que Baudouin quería resolver de forma bilateral, sin intervención alemana, y haciendo unas concesiones mínimas: efectivo cumplimiento del tratado de 1925 sobre los límites de ambas zonas y aceptación del hecho consumado de Tánger ${ }^{5}$.

El 16 de octubre se produjo la sustitución de Beigbeder por Serrano Súñer como ministro de Asuntos Exteriores. Aunque Beigbeder había manifestado al embajador alemán su disposición favorable a la entrada en guerra, su lenguaje con el embajador de Pétaín era muy otro. Con ocasión del viaje de Serrano a Berlín le comentó a La Baume que aquel era de los que estaban dispuestos a vender su patria «por ambición y por estupidez", pero que no eran muchos los españoles tan miopes como para creer que la ruina del Imperio británico fuera cuestión de días. No es por tanto sorprendente que el cambio de ministro fuera bien recibido por Berlín, a cuya directa presión se debió según La Baume la destitución de Beigbeder. No obstante, el 23 de octubre la entrevista en Hendaya entre Hitler y Franco mostró córno las reivindicadiones españolas respecto a Francia resultaban inaceptables para el dictador alemán, para quien el peligro de que se extendiera la sublevación gaullista era más importante que la ayuda militar que pudiera proporcionar España. Al día siguiente de la entrevista de Hendaya se produjo la de Montoire entre

${ }^{4}$ M. P. MELCHOR SANTAOLALLA, «Las relaciones hispano francesas entre el armisticio y las entrevistas de Hendaya y Montoire". En Perspectivas de la España contemporánea. Estudios en homenaje al profesor V. Palacio Atard. Madrid 1986, págs. 470-475.

${ }^{5}$ MAEM, R 2295/5, Lequerica a Beigbeder, Vichy 30/9/40. 
Hitler y Pétain, que supuso el triunfo de la línea colaboracionista auspiciada por Laval, quien inmediatamente sustituyó a Baudouin en Asuntos Exteriores. A partir de entonces el entusiasmo del Gobierno español por entrar en la guerra se enfrió considerablemente ${ }^{6}$.

El otro gran tema en las relaciones bilaterales en la segunda mitad de 1940 fue el de las medidas contra los dirigentes republicanos refugiados en Francia, que desde el punto de vista del Gobierno español no eran suficientemente duras. Las gestiones de Lequerica iban encaminadas a que las autoridades francesas detuvieran a los refugiados republicanos, impidieran su marcha a países neutrales, o concedieran su extradición a España. Logró por ejemplo que se la negara a Azaña el visado para ir a Suiza y que se evitara la partida hacia México de dirigentes como Tarradellas y el ex jefe del Gobierno centrista Portela Valladares. Hubo también casos de extradiciones, pero no faltaban los obstáculos a las peticiones del Gobierno español. El embajador La Baume informaba de que sin satisfacer las pretensiones españolas en ese campo, que interesaba particularmente a Serrano Súñer, no habría mejora en las relaciones ${ }^{\text {? }}$.

En tanto el embajador español, por su intimidad con varios de los dirigentes del nuevo régimen francés, se había convertido en un observador privilegiado de cuanto acontecía en Vichy. Su actitud inicial fue de innegable simpatía hacia la experiencia que se iniciaba, no exenta de dudas en cuanto a su futuro. Desde el primer momento le llamó la atención la tranquilidad de la población, a pesar de la derrota sufrida. «Me parece cada vez más que a la gente, con la conclusión de la guerra, simplemente se le ha quitado un gran peso de encima». Sin embargo percibía claramente que en muchos sectores pervivían la esperanza en un triunfo anglosajón y sobre todo la gran mayoría del pueblo francés tenía un profundo apego al sistema democrático, que supondría un obstáculo para la revolución nacional, carente además de una escuela de pensamiento político en ia que apoyarse. Incluso los grupos de Doriot y del coronel de la Rocque le parecían "una permanente confusión de deseos patrióticos y desatinos democráticos». Los generales, cuya derrota reciente les había privado de prestigio, junto con Laval, el ministro

${ }^{6}$ MAEP, 248. La Baume a Baudouin, 18/9/40 y 10/10/40. Tusell y Garcia QUEIPO DE LLANO. Franco y Mussolini, Barcelona 1985, págs. 102-107 y 112-114. $10 / 12 / 40$.

${ }_{7}$ MAEM, R $1102 / 36$, Lequerica a Beigbeder, $24 / 7 / 40,4 / 8 / 40,9 / 8 / 40,14 / 8 / 40,4 / 9 / 40$ y 
del Interior Marquet y otros políticos de la misma orientación, podrían crear un estado autoritario correcto, pero no darle el ímpetu que tenían las revoluciones nacionales europeas ${ }^{8}$.

Con todo, después de que la Asamblea Nacional votara en julio los plenos poderes a Pétain, Lequerica quedó muy favorablemente impresionado por la habilidad política de Laval, del que hizo el siguiente retrato:

«Insinuante, agudo, con una grata vulgaridad de aldeano hábil, tenaz y al mismo tiempo flexible, tiene excepcionales cualidades este antigüo socialista revolucionario (...). De este pasado turbulento el hijo del carnicero de Chateldon conserva un formidable instinto popular. Un auténtico estilo «pueblo», quizás su mejor cualidad, para dirigir un movimiento de tipo contemporáneo. Por eso probablemente no le podían soportar los ingleses, tan «clase» y tan aristocráticos detrás de su jerigonza democrática. Viéndole comer, por ejemplo, y siguiendo su pintoresco manejo del cuchillo, sacrílego para un británico, comprendo, aún antes de la cuestión de Abisinia, la incompatibilidad inglesa con él. Laval soñaba, como muchas veces he dicho a V.E., con esta transformación de la política francesa." ${ }^{9}$

Respecto a Pétain, opinaba que dado su pasado glorioso y su ascendente moral, el que hubiera asumido su nuevo papel había sido la gran fortuna política para Francia... y para Alemania. Pero la facilidad con que muchos franceses șe disponian a entenderse con los alemanes, le resultaba al embajador español denigrante. También le sorprendia la creencia de algunos dirigentes de Vichy de que bastaba adoptar las ideas totalitarias del vencedor para eludir las consecuencias de la derrota, o su pretensión de lograr el apoyo de Italia y España en tal empresa. Esperaba sin embargo un propósito de moderación en la victoria, "digno del genio de Hitler y Mussolini», que hiciera posible la comunidad espiritual de los distintos pueblos europeos, a la cual podría contribuir un Gobierno francés como el de Pétain, pero no uno impuesto por los alemanes. Las gestiones de Marcel Déat y de Gaston Bergery para la creación de un partido único, "equivalente al partido alemán, español o italiano», le parecieron el camino indicado para la revolución nacional francesa, pero encontraba un gran obstáculo para ésta en la necesidad de conjugar la exaltación patriótica con la aceptación de la victoria alemana, lo que ve-

${ }^{8}$ MAEM, R 2295/4, Lequerica a Beigbeder, Royat 2/7/40.

${ }^{9}$ MAEM, R 2295/4, Lequerica a Beigbeder, Vichy 10/7/40. 
nía a representar "un fascismo de derrota". En cuanto a la idea de que España colaborara en la defensa del catolicismo francés, supuestamente amenazado por Alemania, la rechazaba de plano. No perdonaba a católicos como Mauriac o Maritain su actitud durante la guerra española. Al secretario general del Quai d'Orsay, Charles-Roux, que se lamentaba ante él de que los alemanes hubieran registrado la redacción del diario La Croix, le replicó que hubieran debido tomar medidas más severas, incluso "pegarle fuego», añadió con dudoso sentido del humor. En cambio, estaba dispuesto a destacar cualquier síntoma de un apoyo de Hitler al catolicismo, como su asistencia por sorpresa a una misa durante una visita a París ${ }^{10}$.

En octubre Laval le afirmó temer que en caso de victoria inglesa se impusieran de nuevo en Francia los judíos y el Frente Popular, por lo que, en caso de necesidad, Francia debería incluso entrar en guerra al lado de Alemania. Pétain, con quien Lequerica se entrevistó el 14 de noviembre, mantenía otros puntos de vista. Le manifestó su irritación por las expulsiones de loreneses de lengua francesa y su descontento con ciertas afirmaciones de Laval, aunque a su vez estaba indignado con De Gaulle y el apoyo que le daban los ingleses. Se proponía mantener la neutralidad y preservar la libertad de acción de Francia para el futuro ${ }^{11}$.

El cambio de orientación que supuso la sustitución de Baudouin por Laval en el Quai d'Orsay se tradujo en el cambio de embajador en España. La Baume, que siguiendo instrucciones de Baudouin había hecho de Madrid un centro de contactos franco-británicos, fue reemplazado en octubre por Charles Piétri. Acerca del nuevo embajador, que había sido ministro en el primer Gobiérno de Pétain, la opinión de Lequerica no podía ser más favorable. En su informe a Serrano recordó su «actitud constantemente anti-inglesa y favorable al entendimiento con Alemania", su gratísimo trato, su cualidad de hombre de sociedad y de mundo, "cosa rara entre los políticos franceses", su apoyo a la causa de Franco en la guerra civil, su catolicismo, su íntimo desacuerdo con el régimen republicano desde tiempo atrás. El propio Piétri, en sus memorias, afirma que el Gobierno español se mostró reticente hacía él, en parte por su condición de prohombre de la III República, y que si obtuvo el placet fue

${ }^{10}$ MAEM, R 2295/4, Lequerica a Beigbeder, Vichy 10/7/40, 17/7/40, 18/7/40, 24/7/40, $31 / 7 / 40,8 / 8 / 40$ y $2 / 9 / 40$.

$"$ MAEM, R 2295/5, Lequerica a Serrano, Vichy $24 / 10 / 40$; R $1102 / 36$, Lequerica a Serrano, 14/11/40. 
por la insistencia de Lequerica. Serrano le planteó de entrada la necesidad de una revisión amigable de la cuestión marroquí, mientras que Franco, en la presentación de credenciales, el 6 de diciembre, lanzó una dura filípica contra Francia ${ }^{12}$.

La fundamental desconfianza del embajador español hacia Francia se manifestó con claridad tras la destitución de Laval el 13 de diciembre de 1940. Cuando el embajador alemán Otto Abetz, indignado por la medida que se había tomado contra el principal exponente de la colaboración, acudió a Vichy, con el único diplomático extranjero con el que se puso en contacto fue con Lequerica. Éste aprovechó para ponerle en guardia contra una política como la realizada por los vencedores de 1815, que había permitido a Francia recuperar rápidamente su poderío, y para recalcar en cambio la conveniencia de fortalecer a España como potencia de equilibrio. Este sería un argumento constante de Lequerica en sus contactos con los alemanes. Por ello, aunque considerara lamentable lo ocurrido desde un punto de vista francés, consideró que la crisis del 13 de diciembre podría beneficiar a España, en la medida en que había abierto los ojos incluso a los elementos alemanes más partidarios de la colaboración francesa, como el propio Abetz. Por lo demás su opinión acerca de Pierre-Etienne Flandin, que sustituyó a Laval en el Quai d'Orsay, era excelente, pues le consideraba el estadista de más talla entre los parlamentarios franceses, además de firme partidario de la aproximación franco-alemana. En una conversación que mantuvieron a fines de enero de 1941, Flandin le dijo que era incluso posible que Francia llegara a colaborar militarmente con Alemania en África, pero sólo después de firmado un tratado de paz que precisara el coste de la pasada derrota, y se jactó de ser mucho más capaz que Laval de influir en esa dirección al mariscal. Al embajador español le preocupaba que el precio de tal colaboración fuera a ser un freno a las aspiraciones africanas incluso de la misma Italia beligerante. Pero dudaba de que Pétain fuera a abandonar la política de doble juego y de espera, hasta que la suerte de las armas se inclinara definitivamente a favor de los alemanes o de los anglosajones. Por lo demás, la permanencia de Flandin en el Quai d'Orsay fue efímera, pues el 9 de febrero de 1941 le sustituyó el almirante Darlan, que se convirtió en delfín del anciano mariscal ${ }^{13}$.

${ }^{12}$ MAEM, R 2295/5, Lequerica a Serrano, Vichy 7/10/40. CH. PIETRI, Mes années d'Espagne, París 1954, págs. 27-42. HOARE, Ambassador on Special Mission, Londres 1946, págs. 83-87. J. B. DuRoselle, L'Abîme, 1938-1945, París 1982, págs. 274-275.

${ }^{13}$ MAEM, R 2295/6, Lequerica a Serrano, Vichy $16 / 12 / 40,18 / 12 / 40,24 / 1 / 41$ y 30/1/41. 
España, cuya situación alimenticia era angustiosa, se iba inclinando también hacia su propia política de espera. No es que Franco dudara de la victoria alemana, sino que cada vez tenía menos prisa por entrar en una guerra en que los alemanes apenas le prometían en firme ganancias territoriales. A fines de 1940 Hitler tenía el máximo interés en la entrada en guerra de España, para apoderarse de Gibraltar y asegurarse así el Mediterráneo occidental, pero por el mismo motivo no estaba dispuesto a concesiones a costa de Francia, que podrían tener gravísimas consecuencias en la actitud del ejército francés del norte de África. Recurrió entonces a los italianos para que convencieran a Franco, quien se entrevistó con Mussolini el 12 de febrero. El dictador italiano no parecía sin embargo especialmente interesado en que España se convirtiera en un competidor a la hora del reparto del botín de la victoria y la entrevista apenas tuvo consecuencias prácticas. Semanas atrás, el embajador francés en Roma, Ormesson, había informado a Vichy que en los medios oficiosos italianos la conquista española de Gibraltar, que habría dado a España el control del estrecho, era considerada como una solución peor que el mantenimiento de la neutralidad española y la entrega a España tras la guerra de un Gibraltar desmilitarizado. De regreso desde Italia, Franco se entrevistó con Pétain en Montpellier, pero este contacto fue más protocolario que político. «Quienes soñaban en amistades latinas separadas - comentó Lequerica - han comprobado en el Sur cómo el camino de Madrid pasaba por Roma y Berlín". Lo cierto era que por aquellas fechas Hitler quedó convencido de que Franco no entraría en la guerra, lo cual lamentó no sólo por Gibraltar, sino porque perdía una carta fundamental para poner fin a las vacilaciones de los franceses, como era la amenaza de premiar a España a su costa ${ }^{14}$.

La radical desconfianza española hacia Francia no desapareció por gestos como la disposición francesa a conceder extradiciones, que fueron agilizadas por el ministro de Justicia Joseph Barthélemy. En una cena con el antiguo embajador alemán en Madrid conde Welczeck, en la que éste hizo notar que el sentimiento antifrancés era muy profundo en España, Lequerica argumentó incluso que si las modificaciones territoriales a expensas de Francia creaban una moderada tensión franco-española y franco-italiana, ello no parecía contrario a la dirección germánica de la futura Euro-África. La reticencia de Lequerica le llevó incluso a gestos como el de no asistir a la investidura de Eugenio d'Ors como doctor

14 Tusell y Garcia Queipo de Llano, Franco y Mussolini, págs. 116-124. Pietri, Mes années..., págs. 55-56. MAEM, R 2295/6, Lequerica a Serrano, París 12/3/41. 
honoris causa por la Universidad de Aix-Marsella, debido entre otras cosas a que no quería prestarse a nada que se pudiera interpretar como una protección francesa sobre la cultura española. Lequerica se oponía tajantemente al intento de reducir el significado de la revolución nacional española, "precursora de la gran guerra revolucionaria actual dirigida por los países del Eje», y reducirla a los modestos límites del Portugal salazarista y de la Francia de Vichy, para actuar como honorable segundona de ésta... y ayudarla a conservar su imperio africano ${ }^{15}$.

El entusiasmo inicial de Lequerica hacia el régimen de Vichy se había atenuado notoriamente y cada vez consideraba más difícil que en Francia se llevara a cabo una auténtica revolución nacional. «En este Estado pequeño de Vichy, oligárquico, entonado, en manos de generales y almirantes y funcionarios, de mayoría de edad más que canónica, era mucho pretender hallar el ímpetu y el ardor de las transformaciones profundas ejemplares bien conocidas". La Francia de Vichy era un «Estado balneario", en el que la política de colaboración auténtica con Alemania que representaba Laval había dado paso al attentisme del mariscal y su entourage ${ }^{16}$. En julio de 1941 el embajador hizo acerca de Pétain esta dura pero probablemente correcta observación:

«El lanza a sus hombres, como antes a Laval, en el camino de la colaboración con Alemania, les sigue un trecho, luego se enfría, vacila y acaba por volverse a paralizar la acción de sus colaboradores para encontrar, como recompensa, al aplauso de la opinión anglófila y degaulista que no ha hecho nada por modificar. A Laval lo echó; a Darlan será más difícil, pero por primera vez empiezo a pensar que no es tampoco enteramente imposible» ${ }^{17}$.

La simpatía de Lequerica se decantaba hacia gentes como Jacques Doriot, cuya doctrina era en su opinión la más coincidente en Francia con la de «los grandes movimientos nacional-revolucionarios europeos». Incluso la actitud del Vaticano le parecía criticable al embajador de la muy católica España franquista. El nuncio en Vichy era monseñor Valerio Va-

${ }^{15}$ MAEM, Lequerica a Serrano: R 2295/6, Vichy 5/4/41; R 2295/7, París 29/5/41 y Vichy $11 / 9 / 41 ; R 2295 / 8$, Vichy $9 / 2 / 42$.

${ }^{16}$ MAEM, Lequerica a Serrano: R 2295/6, Vichy $28 / 3 / 41$ y $8 / 4 / 41$; R 2295/7, Vichy $28 /$ $6 / 41$

${ }^{17}$ MAEM, R 2295/7, Lequerica a Serrano, Vichy $27 / 7 / 41$. 
leri, al que consideraba en la órbita anglosajona y al que intentó convencer, un día de mayo de 1941, de que Hitler buscaba la paz, mientras que Roosevelt pretendía el aplastamiento del adversario. Al no condenar el Santo Padre esa actitud anticristiana de Roosevelt, explicaba el embajador al nuncio, caía en una «involuntaria parcialidad hacia el lado bélico". Meses después, los puntos de vista de ambos chocaron a propósito del segundo estatuto judío de Vichy, que Valeri desaprobaba, a lo cual Lequerica le recordó que el Vaticano había felicitado en su tiempo a los Reyes Católicos por medidas mucho más duras. En su informe a Madrid el embajador mostró su preocupación por la actitud de una parte al menos de los medios vaticanos, "con relación a cuestión tan delicada como la de las precisas regulaciones contra los judíos", actitud que atribuía al empeño de no desagradar a Norteamérica y a la hostilidad hacia Alemania ${ }^{18}$.

La España franquista era en general hostil a los judíos, pero concedió visados de tránsito a cierto número de ellos que pudieron abandonar así Francia. La actitud concreta de los responsables españoles no fue homogénea. El consul general en París, Bernardo Rolland, actuó con dedicación en la defensa de los judíos sefarditas a los que Primo de Rivera habia concedido la nacionalidad española, mientras que Lequerica fue mucho más reticente. En marzo de 1942 el embajador informaba a Madrid, que, de acuerdo con las instrucciones recibidas, se ocupaba de defender los derechos de los sefarditas súbditos de España, pero procuraba no olvidar por ello "los principios fundamentales de la revolución española» ni "la internacionalidad del problema semita». Esto en la práctica suponía reducir al mínimo el número de judios españoles a los que prestaba apoyo. Como ejemplo de ello es significativo el caso del destacado industrial de Lyon Benigno Gattegno Boto, que tenía todo el apoyo de la Cámara de comercio española en París y disponía de un certificado de bautismo español. Lequerica, preocupado con la conveniencia de armonizar la defensa de los intereses económicos españoles con uel deber de no estorbar cuantas medidas en los diferentes países del mundo» fuera preciso adoptar "en evitación de un grave peligro internacional», planteó la posibilidad de que el certificado fuera falso al Ministerio de Asuntos Exteriores español que, sustituido ya Serrano por Jordana, reafirmaría su validez. Esta gestión de Lequerica tuvo lugar en julio de 1942, un mes después de que hubiera tenido lugar en París la masiva redada

${ }^{18}$ MAEM, R 2295/8, Lequerica a Serrano, Vichy 6/1/42 y 21/1/42. R 2295/7, Lequerica a Serrano, Vichy $17 / 5 / 41$ y 15/9/41. LotTMAN, Pétain, págs. 395-396. 
de judíos, conocida como del Velódromo de invierno. La actitud contraria tomada por la mayor parte de la Iglesia de Francia la consideraba «al servicio de la agitación internacional filojudía» y le parecía "puramente política y destinada a servir los intereses militares de una problemática revancha francesa«. Algo le tranquilizó al embajador francés en el Vaticano, Léon Bérard, según el cual, Pío XII y el cardenal secretario de Estado se mostraban mucho más cautos y reservados ${ }^{19}$.

La reticencia hacia Francia y la incondicional admiración hacia Alemania del embajador español se tradujeron en una sorprendente sugerencia que hizo a Laval y a Serrano. Se refería a los refugiados españoles en Francia que, en número de unos 120.000 y distribuidos en campos de concentración y grupos de trabajo, era sometidos a duras condiciones con una paga miserable. Algunos cónsules le informaban de que, muchos de ellos querían repatriarse, pero como esta solución era problemática lo mejor, según Lequerica, sería enviar un buen número de ellos a Alemania, donde el contraste con el trato que se les daba en Francia contribuiría a su regeneración ${ }^{20}$.

A comienzos de abril de 1942 Franco, que rara vez recibía a embajadores, concedió audiencia a Piétri. El dictador no descendió a cuestiones concretas, sino que, como solía hacer en tales ocasiones, se movió en un terreno muy general. Expuso su convencimiento que no había más opción que el comunismo o el fascismo. En los países latinos este último habría de ser "templado y ennoblecido por el catolicismo", pero el necesario concurso de éste no estaba siendo promovido por el Vaticano, que conservaba un complejo de liberalismo ${ }^{21}$.

El 18 de abril de 1942 Laval sustituyó a Darlan en la jefatura del Gobierno francés. La opinión de Lequerica sobre él seguía siendo excelente y les unía una amistad estrechísima. Le atribuía un positivo interés político por España y un genuino deseo de unión latina, no entendida como contrapuesta a Alemania, como era el caso de otros políticos franceses, sino basada en la amistad con ésta. Lequerica temía que el acer-

19 MAEM, R 2295/8, Lequerica a Serrano, Vichy $16 / 3 / 42$; R $1175 / 21$, Lequerica a Serrano, Vichy 15/7/42. R 2295/9, Vichy, Lequerica a Serrano, 1/9/42; Lequerica a Jordana, $7 /$ 9/42. H. AvNI, España, Franco y los judíos, Madrid 1974, págs. 77-87, 157-158 y 173-180. A. Marquina, y G. I. Ospina, España y los judíos en el siglo XX, Madrid 1987, págs. 145156 y $164-197$.

${ }^{20}$ MAEM, R 2295/9, Lequerica a Serrano, Vichy 2/5/42.

${ }^{21}$ MAEP, 247, Piétri, Madrid 13/4/42. 
camiento a Alemania que Laval llevaría a cabo fuera perjudicial para las pretensiones de España e Italia, pero con el paso de las semanas, comenzó a creer que el jefe de Gobierno se estaba dejando contagiar por el espíritu de pasividad de Pétain ${ }^{22}$.

En la propia España, sin embargo el entusiasmo por la colaboración con el Eje, que Lequerica mantenía íntegro, se iba enfriando. El 3 de septiembre hubo un cambio de Gobierno, que tuvo su origen en la política interna, pero que se tradujo en la vuelta de Jordana, neutralista convencido, al Ministerio de Asuntos Exteriores, en sustitución de Serrano. En los medios de Vichy menos favorables al colaboracionismo el cambio fue muy bien acogido y comparado incluso con la caída de Laval el 13 de diciembre de 1940, interpretación que Lequerica combatió y que se debilitó al comprobar el tono que mantenía la prensa española. En efecto, el cambio de Gobierno no representó en absoluto un giro brusco en la política española. Jordana se lo dijo asi a Piétri, al tiempo que le prometió que frenaría los ataques de la prensa española a Francia, que venian siendo continuos a causa de las reivindicaciones africanas. En realidad tardó en conseguirlo. A los alemanes por otra parte, o al menos al embajador en Francia Abetz, tales campañas de prensa, lo mismo que las italianas, les parecian inoportunas porque dificultaban la acción de los Gobiernos colaboracionistas de Vichy. Así se lo dijo a Lequerica, quien no dejaba de lamentar que la línea de acuerdo con Francia que representaba Abetz, con el apoyo de Ribbentrop, se interpusiera siempre frente a las aspiraciones españolas ${ }^{23}$.

El desembarco aliado en el África del Norte francesa, el 8 de noviembre de 1942, tuvo consecuencias importantes tanto para España como, sobre todo, para Francia. Aquélla no sólo vio disiparse del todo sus sueños marroquíes, sino que quedó expuesta a una creciente presión aliada, mientras que el régimen de Vichy con el paso de las tropas africanas a la disidencia, el sabotaje de la flota por los propios marinos y la ocupación de la zona libre por los alemanes, perdió todas las bazas que hasta entonces le habían consentido al menos una apariencia de autonomía. Desde ese momento las relaciones entre Madrid y Vichy pierden todo significado y el papel de Lequerica queda reducido a poco más que

${ }^{22}$ MAEM, R 2295/9, Lequerica a Serrano, Vichy $15 / 4 / 42$ y $7 / 7 / 42$.

${ }_{23}$ MAEM, Lequerica a Jordana, R 2295/9, Vichy 9/9/42; R 2295/10, París 2/11/42. MAEP, 247, Piétri, Madrid 15/9/42. PIETRI, Mes années d'Espagne, pág. 65. 
el de simple testigo de la agonía de un régimen ${ }^{24}$. Hasta el final de su misión el embajador español siguió aferrado a su orientación germanófila, pero la política exterior de Franco, contra la voluntad de éste, hubo de irse modificando como consecuentica de las nuevas circunstancias.

24 He recogido las observaciones de Lequerica acerca de la etapa final de Vichy en mi artículo «El ocaso de un régimen. La política de Vichy en los informes del embajador español, 1942-1944", en Haciendo historia. Homenaje al profesor Carlos Seco. Madrid 1989, págs. $581-588$. 